\title{
Multidimensional Facets of Perceived Risk in Mobile Travel Booking
}

\author{
Sangwon Park (Corresponding author) \\ Senior Lecturer \\ School of Hospitality and Tourism Management \\ University of Surrey \\ $15 \mathrm{AP} 02$ \\ Guildford, Surrey, GU2 7XH United Kingdom \\ Tel: 44(0)1483689660 \\ Fax: 44(0)1483686346 \\ e-mail: sangwon.park@ surrey.ac.uk \\ and \\ Iis P. Tussyadiah \\ Associate Clinical Professor \\ School of Hospitality Business Management \\ Carson College of Business \\ Washington State University Vancouver \\ 14204 NE Salmon Creek Ave, CLS 308T \\ Vancouver, WA 98686 USA \\ Phone: +1 (360) 546-9109 \\ Fax: +1 (360) 546-9037 \\ Email: iis.tussyadiah@wsu.edu
}




\begin{abstract}
Despite the growing prevalence of smartphones in daily life and travel context, travellers still perceive an extent of risk associated with using their smartphone to book travel products. In order to alleviate or reduce perceived risk, it is important to better understand the dimensions of and the factors that contribute to perceived risk. This study analysed 411 responses from an online panel to examine perceived risk in mobile travel booking and identified the following facets: time risk, financial risk, performance risk, privacy/security risk, psychological risk, physical risk, and device risk. Several antecedents of perceived risk were identified. Perceived collection of personal information via smartphones contributes positively, while consumer innovativeness, trust, and visibility contribute negatively to perceived risk. Further, the predictive validity of perceived risk is confirmed as it significantly explains perceived usefulness, attitude, and behavioural intention in mobile travel booking. Implications to manage perceived risk and its antecedents are provided.
\end{abstract}

Keywords: Perceived Risk; Smartphone; Travel Booking; Mobile Booking 


\section{Introduction}

Mobile technology has reshaped travellers' behaviour, from the ways they retrieve and process information, to how they communicate with service providers and amongst themselves (Wang, Park and Fesenmaier, 2012). Using mobile systems with such features as wireless interface and location-based services, travellers are able to search for information anytime to meet their spontaneous needs and acquire personalized information to fulfil their mobility-related desires (Anckar and D'Incau, 2002). Indeed, there has been an increasing number of smartphone users who accessed travel-related content. However, the share of those who book travel products on smartphones is still relatively low. Based on a study among travellers in the United States, eMarketer (2015) shows that while the percentage of online travel bookers who use mobile phones is expected to increase to $51.8 \%$ in 2016 (compared to $25.6 \%$ in 2013), it is still less than that of mobile travel researchers, which is expected at $73 \%$ in 2016. This shows that while travellers use mobile technology until the alternative evaluation stage of decision making process (Dewey, 1910; Engel, Kollat, and Blackwell, 1968), they seem to face a significant challenge to complete transactions using mobile devices.

Perceived risk, which stands for a consumer's belief about the potential uncertainty associated with negative outcomes in a purchase situation, is one of the main barriers that make consumers reluctant to perform purchase decisions (Kim, Ferrin and Rao, 2008). Perceived risk in mobile shopping is due to lack of evidence of discrepancies between consumers' pre-purchase evaluation and actual product qualities. In particular, purchasing travel products using mobile devices is distinctively different from traditional and internet shopping contexts, because of various issues associated with hidden and unconscious computing, location-aware systems, smaller screens, and instant activities (Yang and Zhang, 
2009). Moreover, as mobile devices are considered self-service technology, mobile shopping places a considerable burden and responsibility on the consumers (Cunningham, Gerlach, Harper, and Young, 2005). Consumers making purchases on a mobile device are required to search for extensive information from multiple intermediaries, compare prices, and book properly (Law and Leung, 2000). The loss resulting from an improper decision becomes the sole blame of the consumers, who have very limited recourses to correct any transaction errors.

Moreover, in the early adoption stage of an IT-enabled artefact such as smartphones, people are uncertain not only about the services they look for, but also about the soundness of the underlying technology platform. These induce increasing risk concerns from travellers when purchasing tourism products using mobile devices (Luo, Li, Zhang, and Shim 2010). Considered as experiential or credential products, tourism services are generally intangible, providing travellers with limited cues or information to assess the product or service quality before actual experiences (Chen, Lee and Wang, 2012; Eggert, 2006). The intangibility of tourism services may reduce travellers' confidence on their decisions and, thus, increase risk perception. This dual uncertainty associated with mobile technology and tourism emphasises the importance of research to understand the major dimensions of risk perceived by travellers and to identify the antecedents that contribute to perceived risk when purchasing tourism products using mobile devices (Luo et al., 2010).

In fact, tourism researchers have paid a considerable attention to the adoption of mobile technology and its role in enhancing travel experiences. However, research assessing perceived risk as one of the inhibitors for consumer choice is a paucity in information technology and tourism fields (Kim, Kim and Leong, 2005). Following the multi-dimensional model of perceived risk, as suggested by Jacoby and Kaplan (1972), a number of researchers in information management suggested its relevance and suitability to mobile services studies 
(Lee, McGoldrick, Keeling, and Doherty, 2003). Therefore, this research (1) proposes the multi facets of risk perceived by travellers when they use mobile devices to purchase tourism products and (2) identify the factors that associate with perceived risk so that the suggestions to alleviate these risks can be provided.

\section{Literature Review}

Perceived Risk in Tourism and ICT

Since the 1960s, the theory of perceived risk has been utilized to explain consumer behaviour. Cunningham (1967) suggests that risk consists of two dimensions: uncertainty and consequences. That is, risk is composed of the size of potential loss (or the subjective possibility of loss) if the results of an act were not favourable and the individual's subjective feelings of certainty that the outcome will be unpleasant (Lee, 2009). While several refinements to define risk have been approached in terms of expected value theory (Cunningham, 1967) and expected utility theory (Bonoma and Johnston, 1979; Currim and Sarin, 1983), risk remains a subjectively determined expectation of loss by consumers, referring to perceived risk (Cunningham et al., 2005).

Along these lines, perceived risk has been considered as an influential element in understanding consumer behaviour since consumers are more often motivated to avoid mistakes than to maximise utility in purchasing (Mitchell, 1999). People usually do not have sufficient knowledge required to encompass learning of the products, leading to an increased risk perception in complex buying behaviour (Mitchell, 1992). For example, purchasing expensive products may result in financial loss, products that are highly expressive in nature may bring about significant psycho-social loss, and unfamiliar products will give rise to uncertainty. In this vein, previous researchers concurred that the more risk people perceive in a buying situation, the less likely they will purchase (Dowling and Staelin, 1994). 
Particularly, perceived risk can become more important in a travel context due to the intangible nature of tourism services (Ruiz-Mafé, Sanz-Blas, and Aldás-Manzano, 2009). Since travellers are unable to physically examine tourism products prior to purchase, their perception of and experiences with the products can only be evaluated during consumption. As a result, a purchase of tourism products generates high uncertainty as to their outcomes (Nepomuceno, Laroche, and Richard, 2013). Tourism scholars have endeavoured to demonstrate the notions and dimensions of perceived risk with regards to destination choice (Fuchs and Reichel 2006; Moreira, 2007), selection of travel modes (Boksberger, Bieger, and Laesser, 2007), and decisions particularly related to international travel (Seabra, Dolnicar, Abrantes, and Kastenholz, 2013; Sonmez and Graefe, 1998). However, perceived risk has not been widely researched to further understand online communication and shopping behaviour in tourism (Kim, et al., 2005). It is argued that the dimensions of perceived risk may vary according to products (or services) and contexts (Featherman and Pavlou, 2003; Lee, 2009). Risk perception, therefore, should be investigated using measures that fit to the specific context of interest (Roehl and Fesenmaier, 1992). Accordingly, the following part reviews literature of perceived risk focusing on the usage of online services.

When purchasing products, people associate online channels with higher risk compared to traditional channels (Ko, Jung, Kim, and Shim, 2004). In general, online environment does not provide sufficient chances for consumers to physically inspect the products, which increases information asymmetry and, in turn, escalates the consumption uncertainty (Park and Nicolau, 2015). The limited interaction with service providers causes consumers to feel insecure of potential deception and difficulties to reclaim flawed products in an online system (Bhatnagar and Ghose, 2004). Therefore, perceived risk of online transactions reduces perceived behavioural and environmental control and, subsequently, the lack of managerial control negatively affects usage of online technology for shopping. 
In order to understand the adoption of e-services, Featherman and Pavlou (2003) applied Technology Adoption Model (TAM), based upon a proposition that consumers consciously and unconsciously perceive risk when evaluating services for purchase or adoption. They proposed a multi-dimensional risk perception and identified an inhibiting influence of risk on technology adoption behaviour. Subsequently, a number of studies in information management confirmed the multi-dimensional nature of perceived risk and suggested the importance of risk in predicting consumer behaviour for Internet/mobile banking (Lee, 2009; Luo et al., 2010), shopping (Forsythe and Shi, 2003; Crespo, del Bosque, and de los Salmones, 2009), and entertainment (Chen et al., 2012). Martins, Oliveira, and Popovič (2014) showed a significant role of perceived risk in understanding e-service behaviour by proposing an integrated model using United Theory of Acceptance and Use of Technology (UTAUT). Comparing perceived risk and benefits, it was identified that risk outweighs perceived benefit of online activities for banking (Lee, 2009) and shopping (Bhatnagar, Misra, and Rao, 2000). Additionally, the negative effects of perceived risk are also found in online information exchange (Zimmer et al., 2010), information search, and transaction behaviour (Forsythe and Shi, 2003).

Tourism research that investigated perceived risk in online consumption mainly focused on airline reservation. Kim et al. (2005) proposed six types of risk perception and showed its negative relationship with intention to purchase airline tickets. Various studies applied TAM to estimate the relative importance of perceived risk across ease of use, usefulness and trust in forming attitude towards online booking (Nunkoo and Ramkissoon, 2013) and behavioural intention of online travel purchase (Amaro and Duarte, 2015). Cunningham et al. (2005) examined the effects of risk across all phases of the consumer buying process and found that the types of risk deemed significant are different depending on the different stages. Importantly, they concluded that perceived risk plays a prominent role in 
the moment when online travellers purchase services, which supports the importance of this research. Being able to recognize the negative influences of perceived risk, efforts to alleviate risk can be made, such as helping travellers find useful information (Mitchell, Davies, Moutinho, and Vassos, 1999), using bundled products (Shikhar, Sego, and Chanvarasuth 2003), brand loyalty/reputation (Kim, Qu, and Kim, 2009), and transparent privacy policy (Lin, Jones and Westwood, 2009).

\section{Facets of Perceived Risk}

Consumers perceive several types of risk when they purchase products using advanced technology (Kim et al., 2009). Jacoby and Kaplan (1972) identified five facets of perceived risk: financial risk, performance risk, social risk, physical risk and psychological risk. Following these, McCorkle (1990) added a dimension of time risk that reflects the potential time loss between order and fulfilment. Security and/or privacy issues were regarded as an important concern in online shopping (Crespo et al., 2009). Since consumers need to provide sensitive information (e.g., credit card number) while transacting for products via the Internet, consumers' anxiety due to the limited information about products and vendors is likely to be a considerable issue. In this vein, Featherman and Pavlou (2003) proposed a comprehensive model of perceived facets of risk, comprising time, psychological, privacy, financial, performance, and social risks. They supported a second-order composite of perceived risk and identified that social risk is not important to define the generic risk perception along with other risk dimensions in e-services context. Numerous studies have applied those six facets to measure perceived risk in various fields, confirming the application of traditional risk facets to understand the perception of online consumers.

Importantly, perceived risk is situation specific. The types of risk should be formed with consideration of a particular situation encountered by an individual. Consumers using 
innovative technologies (i.e., smartphones) that they are relatively less familiar to and knowledgeable of compared to other devices (e.g., PCs) face challenges from possible malfunctions, such as devices running out of battery or consumers unable to access or interact with an application (e.g., due to frequent upgrade requirements) (Kim et. al., 2013; Yang and Zhang, 2009). These suggest technological complexity as a facet of risk (Bhatnagar et al., 2000). This argument has been discussed by tourism scholars, calling it equipment risk, which represents the possibility of mechanical or equipment problems that prevent travellers from achieving desired trip experiences (Roehl and Fesenmaier, 1992; Sonmez and Graefe, 1998; Tsaur, Tzeng, and Wang, 1997). The results of Roehl and Fesenmaier (1992)'s study revealed that equipment risk is the highest risk facet in travel decision making process. Accordingly, it can be argued that the specific risk associated with technological device that enables travellers to purchase travel products is noteworthy in this research.

Table 1 summarises a variety of perceived risk facets examined in general online services and in tourism fields. The following briefly describes the definitions of perceived risk facets examined in this research (see Featherman and Pavlou, 2003; Forsythe and Shi, 2003; Kim et al., 2005; Mitchell, 1992; Yang and Zhang, 2009):

- Financial risk refers to the risk that mobile services used to purchase a travel product will not make the best possible monetary gain for a traveller;

- $\quad$ Performance risk refers to the possibility of mobile services not performing as it was designed and advertised and therefore failing to deliver desired benefits;

- $\quad$ Social risk refers to the potential loss of status in one's social group as a result of using mobile services, such as looking untrendy;

- Physical risk refers to the possibility that using mobile services to book a travel product results in a health hazard to a traveller; 
- $\quad$ Psychological risk refers to the risk that the selection of mobile services to purchase a travel product will have a negative influence on a traveller's peace of mind or selfperception;

- $\quad$ Time risk refers to the risk that a traveller will not only waste time and efforts, but also lose convenience when making a purchase decision that did not perform his/her expectation (e.g., disorganized or confusing mobile application/websites that are too slow to download and load the services);

- Privacy risk refers to the potential loss of control over personal information, such as when information about a traveller is used without his/her knowledge or permission;

- $\quad$ Security risk refers to the risk involving transmitting sensitive data through mobile transaction, such as concerning potentially malicious individuals (or services) that breach technological data protection; and

- Device (or technology) risk refers to the potential loss caused or intercepted by unreliable technology of mobile services.

\section{[Insert Table 1 here]}

Based on the conceptualizations of perceived risk in the context of mobile travel consumption, this study proposes:

H1: Perceived risk comprises the facets of (1) financial, (2) performance, (3) social, (4) physical, (5) psychological, (6) time, (7) privacy, (8) security, and (9) device risk.

\section{Antecedents of Perceived Risk}

Literature has suggested various factors that influence perceived risk in general consumption settings (Conchar, Zinkhan, Peters, and Olavarrieta, 2004; Dholakia, 2001; Dowling and Staelin, 1994) and in consumption contexts where information technologies are involved (Donthu and Garcia, 1999; Lim, 2003). These factors are associated with consumers, 
vendors, technology, and contextual characteristics. Among consumers, perceived risk processing is pervasively influenced by individual characteristics (Conchar et al., 2004), particularly the enduring traits of individuals related to uncertainty and risk. These traits, while termed differently in previous studies, such as risk aversion (Kahneman and Tversky, 1987), risk tolerance (Sitkin and Pablo, 1992), and risk-taking propensity (Bromiley and Curley, 1992), are useful in predicting consumers' risk-taking behaviour (Conchar et al., 2004). Especially, studies proposed consumer innovativeness traits as an antecedent of perceived risk in consumption contexts involving technological systems (e.g., AldásManzano, Lassala-Navarré, Ruiz-Mafé, and Sanz-Blas, 2009). Consumer innovativeness manifests in novelty seeking behaviour (Hirunyawipada and Paswan, 2006), which includes adoption of new products and services that might be viewed as risky by other consumers (von Hippel, 1986). Indeed, consumer innovativeness traits are positively associated with online shopping behaviour (Citrin, Sprott, Silverman, and Stem, 2000; Limayem, Khalifa, and Frini, 2000), purchase intention for travel products (San-Martín and Herrero, 2012), online information search behaviour (Couture Arcand, Sénécal, and Oullet, 2015), and use of smartphones in travel (Tussyadiah, 2015). These aforementioned studies confirm that innovative consumers demonstrate higher risk-taking propensity. Therefore, it can be suggested that:

$\mathrm{H} 2$ : Consumer innovativeness has a negative effect on perceived risk in mobile travel booking.

Secondly, previous research suggest trust as a factor that influences perceived risk among consumers (Cheung and Lee, 2000; Kim, et al., 2008). Trust is defined as one person's behavioural basis for his/her belief about the characteristics of another (Mayer, Davis, and Schoorman, 1995), a consumer's willingness to behave in a manner that assumes another party will behave in accordance with expectations (Deutch, 1960). In any 
consumption situations, unless trust is involved, consumers are naturally hesitant to make purchases (Gefen, Rao, and Tractinsky, 2003; Jarvenpaa and Tractisnky, 1999), making trust a prerequisite of successful commerce. In consumption contexts involving mobile technology, consumers take chances from the uncontrollable future and the free actions of others, such as vendors, agents, technologies. Trust is crucial in dealing with these uncertainties. Previous studies show that trust is negatively associated with perceived risk (e.g., Aloudat, Michael, Chen and Al-Debei, 2014; Cheung and Lee, 2000). This hypothesis has been confirmed in online shopping, where consumers' trust toward internet vendors is negatively associated with their perceived risk (Cheung and Lee, 2000), and in adoption of location-based services on mobile devices (Aloudat et al., 2014). Therefore, it can be suggested that:

H3: Trust toward smartphone use has a negative effect on perceived risk in mobile travel booking.

Another antecedent of perceived risk suggested in the field of information technology is visibility, which is defined as consumers' exposure to and ability to observe the applications of technology in a consumption situation (Aloudat et al., 2014; Leung and Wei, 1999). This factor is also called observability (Rogers, 1995) as well as demonstrability and communicability (Moore and Benbasat, 1991), which is the degree to which the results of technology innovation are visible to (can be observed by) others. In the case of mobile booking, visibility, visibility refers to the extent to which consumers are exposed to and/or able to observe the use of smartphones to make travel reservation. Zaltman, Duncan, and Holbek's (1973) propose that innovation with more visible advantages is more likely to be adopted. Visibility reduces uncertainty associated with purchasing intangible travel products using unfamiliar technologies. Hence, it is suggested that: 
H4: The visibility of smartphone use for travel booking has a negative effect on perceived risk in mobile travel booking.

Finally, a factor associated with perceived risk of using smartphones is collection of personal information. Smartphones are equipped with applications that automatically collect and store users' information, such as transaction history and locational data. While turning on location services may assist in decision making processes through context-aware recommendation systems, consumers generally regard personal location information as highly sensitive. Previous studies suggest that consumers have concerns of privacy risk as a result of their smartphones collecting an extensive amount of personal data and sharing identifiable information with vendors and other service providers (Aloudat et al., 2014; Junglas and Spitzmüller, 2005). Therefore, it is hypothesized that:

H5: Perceived collection of personal information through smartphones has a positive effect on perceived risk in mobile travel booking.

\section{Methodology}

\section{Measurement Development}

Measurement items were drawn from related literature and revised to accommodate the context of mobile booking for travel products. A carefully structured instrument was used to measure the theoretical variables using a five-point Likert scale. The questionnaire consists of four sections. The first part asked respondents about their experiences in the most recent trip in order to understand travel behaviour, such as number of trips in the last 12 months, length of stay in the most recent trip, number of travel companions, travel budget, and planning horizon. The second section inquires of respondent's usage and perception of using 
smartphone, including its operating system, time spent using smartphone per day, and past experience booking accommodation using smartphone, as well as technological innovativeness (Agarwal and Prasad, 1998; Goldsmith and Hofacker, 1991), trust (Junglas and Spitzmuller, 2005), visibility (Aloudat et al., 2014; Karahanna, Straub, and Chervany, 1999), and collection of sensitive information (Aloudat et al., 2014; Junglas and Spitzmüller, 2005). The third section measures perceived risk facets: social risk, time risk, financial risk, performance risk, security risk, privacy risk, psychological risk and device risk (Featherman and Pavlou, 2003; Kim et al., 2005, 2013; Rotchanakitumnuai, 2007). Additionally, three variables about online travel behaviour were asked in order to test the predictive validity of perceived risk, such as perceives usefulness (Aloudat et al., 2014), attitudes toward and intention to use smartphones to purchase travel products (Kuhlmeier and Knight, 2005; Wu and Wang, 2005). The final section seeks demographic information, which includes gender, age, level of education, and job position.

\section{Procedure}

Before collecting actual data, in order to reduce the measurement error, content validity was checked by inviting academic experts including doctoral students and academic staffs in relevant field to identify ambiguous definition or questions that are difficult to answer. Once face validity was confirmed, the questionnaire that was developed in English was translated into Mandarin and then translated back to English. The back translation method was used to avoid translation errors and maintain consistency of the meanings conveyed in words (Brislin, 1986; Park and Reisinger, 2012). Two versions of surveys, in English and Chinese, were sent to 20 Chinese postgraduate students who study tourism in the UK in order to re-check the content validity. 


\section{Data Collection}

Online survey was distributed via an online marketing research company that encompasses one of largest online consumers in China (www.sojump.com). This company distributed webbased surveys to randomly selected panel members. In order to identify valid sample for this study, a couple of filtering questions were asked to the survey recipients: (1) "Have you used smartphone in everyday life?" and (2) "Did you use smartphone to search for information about accommodation in the most recent trip?" Of 1,300 invitations, 411 respondents (18 years and older) meet the sample requirements and completed all of the questionnaires, which refers to $31.6 \%$ of response rate.

\section{Data Analysis}

First, descriptive analysis was conducted to understand the characteristics of respondents and to identify the distributions of data relevant to the variables in the theoretical model. Then, Structural Equation Modelling (SEM) assessed the proposed relationships by estimating measurement and predictive hypotheses (Bagozzi and Yi, 2012). Specifically, SEM was conducted following two steps: (1) assessment of latent variables along with levels of observations (i.e., measurement model) and (2) testing the proposed relationships between latent variables on the theoretical level (i.e., structural model). Confirmatory Factor Analyses (CFA) estimated the measurement model to check reliability and validity of the constructs with maximum likelihood estimation using M-Plus software. A number of methods for the model's fit considered factor loadings (or indicator reliability) (above 0.70), composite reliability of the latent constructs (above 0.70$)$, chi-square $\left(\chi^{2}\right)$, Comparative Fit Index (CFI) (above 0.90), Tucker-Lewis Index (TLI) (above .90), root mean square error of approximation (RMSEA) (less than 0.05), and root mean square residual (RMSR) (less than 0.05) (Nunnally and Bernstein, 1994). Next, a second-order CFA was performed to measure 
the relative importance of each risk facet with regards to the consistent goodness-of-fit indices as well as AIC (Akaike Information Criteria) to compare between the original and modified CFA models (Kline, 2010). Importantly, this study includes the tests for common method bias as the same measurement medium was used to collect data for all constructs. Based upon the suggestions by Podsakoff, et al., (2003), this research adopted three different approaches: Harman's single factor test, correlation matrix, and a latent variable approach (or the marker variable method).

\section{Results}

\section{Profiles of Respondents}

It shows that female $(57.4 \%)$ is slightly more than male (42.6\%) and approximately $78 \%$ of respondents are 30 years or younger. Most respondents have a Bachelor degree $(75.7 \%)$ and are employed in private companies $(60.6 \%)$. In terms of travel behaviour, respondents had 2.96 trips on average in the past 12 months. Approximately half of travellers (54.5\%) have taken trips for 3-5 days; about 77\% travel with 1-4 companions; travellers planned their journey for 2-6 days (34.1\%) and 1-2 weeks before departures (31.4\%). With regards to smartphone behaviour, nearly $50 \%$ of respondents used their mobile phones more than 4 hours per day; $65 \%$ has booked accommodation using their smartphones.

\section{Assessing Measurement Model}

A first-order CFA was conducted to estimate the ability of the indicators to measure the theorized risk facets. Initially, all factor loadings that reflect individual risk concepts were checked, and an item measuring time risk was removed due to loading below the cut-off value: $T R \_1=0.54$. As a result, all factor loadings are over 0.60 , indicating that interrelations 
are significantly high in magnitude $(p<.001)$ (Kline, 2010). As shown in Table 2, each risk facet exhibited strong internal reliability as represented by Cronbach's alpha.

[Insert Table 2 here]

The square root of Average Variance Extracted (AVE) was estimated to check the convergent validity for eight latent constructs for risk facets. The values are then compared with other constructs to assess discriminant validity. The results show that AVEs (the meansquared loading for each construct) are larger than the cross-correlations of other risk constructs, which suggests the individual reflective construct is distinct from other constructs in the measurement model. The squared AVE of each risk construct is also over 0.84, demonstrating that the latent variables explain its indicators more than the error variance, confirming convergent validity (see Table 3 ). The correlation result was checked and collinearity between security and privacy constructs was identified $(r=0.93)$. As a result, these two constructs were merged into a single factor, called privacy/security risk (consistent with Bhatnagar et al., 2000; Kim et al., 2008; Lee, 2009). Composite reliability presents acceptable values: social risk (0.88), time risk (0.91), financial risk (0.92), performance risk (0.91), privacy/security risk (0.97), psychological risk (0.95), physical risk (0.91), and device risk (0.82) (see Table 3).

\section{[Insert Table 3 here]}

In order to understand the underlying facets of the composite risk, the following assesses a second-order model of the risk construct. The goodness-of-fit indices for CFA reasonably fits; the value of $\chi^{2} / d f(2.83)$ is lower than the cut-off level 3.0 (Klien, 2011), CFI $=0.92$ and TLI $=0.92$, as well as RMSEA $=0.07$ and SRMR $=0.10$. While the value of RMSEA is slightly higher than recommended $(<0.05), \mathrm{Hu}$ and Bentler (1999) suggested that error values below 0.10 are deemed acceptable (see Table 4). Specifically, when investigating the variance explained for individual risk facets, the explained variance of $10.6 \%$ for social 
risk implies that this risk is not important and salient. Moreover, the correlation values of social risk not only show inconsistent relationships to other constructs, but also of inconsiderable magnitude (i.e., $r<0.16$ ) (see Table 4). This finding is consistent with several studies in e-commerce and m-service adoption, including Featherman and Pavlou (2003), Luo et al. (2010) and Ruiz-Mafé et al. (2009). The findings also reveal that travellers mainly consider performance risk in purchasing tourism products. While physical risk $(\beta=0.68, p<$ 0.001) was not concerned as important as performance risk, it is suggested that the affectbased measurement that assesses personal loss was deemed insightful. Thus, further analysis includes physical risk, whereas social risk was eliminated.

\section{[Insert Table 4 here]}

Figure 1 presents the results of the revised second-order CFA model for perceived risk. The path coefficients for seven risk facets are statistically significant. Comparing the goodness-of-fit to the original model, all fit indices are improved: $\chi^{2} / d f=2.70, \mathrm{CFI}=0.94$, $\mathrm{TLI}=0.93, \mathrm{RMSEA}=0.06$ and $\mathrm{SRMR}=0.05$. In particular, AIC of the revised model $(\mathrm{AIC}$ $=24556.31)$ was a better fit than the original model $(\mathrm{AIC}=28011.04)$ and alternative model with social risk $(\mathrm{AIC}=27921.52)$. This indicates that the removal of social risk forms perceived risk in a better way (see Table 5).

[Insert Figure 1 here]

[Insert Table 5 here]

\section{Estimating the Structural Model}

Figure 2 presents the estimates obtained from the structural model using SEM analysis. The paths indicating perceived risk with seven risk facets are statistically significant $(p<0.001)$, which assure the validation of a second-order model. In terms of antecedents to the perceived risk, innovativeness $(b=-0.19, p<0.001)$ and trust $(b=-0.40, p<0.001)$ negatively influence, 
whereas collection $(b=0.17, p<0.01)$ positively influence perceived risk. However, visibility ( $b=-0.08, p>0.05)$ is not statistically significant to affect the endogenous variable. The $R^{2}$ value of 0.40 indicates that the model explains a substantial amount of variance in perceived risk. Then, the post-hoc statistical power was calculated to test the insignificant relationship between visibility and perceived risk (Cohen, 1988). The observed statistical power (0.99) indicates the probability of relationship at .001 , suggesting that the chance of a Type II error occurring for the specific hypothesized relationship is very restricted.

[Insert Figure 2 here]

\section{Common Method Bias}

Podsakoff et al. (2003) suggests that common method bias tends to be more noticeable and prevailing in studies when data for exogenous and endogenous variables are obtained from the same respondents in the same context utilizing the same item and similar characteristics of instruments. Hence, this research conducted three steps to assess the potential errors in the model. First, Harman's single factor test was conducted by emerging single factor from exploratory factor analysis. The unrotated principal component analysis including eleven factors counts for $37.60 \%$ of the total variance, below the cut-off value of $50 \%$. Second, the correlation matrix presents values below 0.75 , which did not indicate extremely high correlations $(r>0.90)$ (see Table 6). Last, following Podsakoff et al. (2003), a marker factor approach was used by adding a first-order unmeasured factor that specifies with all of the indicators explaining constructs in the proposed model. The changes of model fit indices for the model and factor loadings are compared with the one excluding the method factor. The results indicate that the inclusion of a marker factor does not significantly improve the general model fit compared to the revised measurement model without the method factor. 
Therefore, the results of three different estimations to test common method bias reveal limited common method errors in the analytical model.

[Insert Table 6 here]

\section{Estimating Predictive Validity of Perceived Risk}

This study estimated the predictive validity of perceived risk by comparing to other constructs representing online travel behaviour. Based on previous literature in tourism and information system, it is identified that perceived risk has a negative relationship with cognitive evaluation (i.e., usefulness) of (Lee, 2009) and behavioural responses to using advanced technology (Kuhlmeier and Knight, 2005; Wu and Wang, 2005). Perceived risk that is attributable to the use of information technology has been shown to inhibit product evaluation and adoption (Dowling and Staelin, 1994). It was suggested in multiple studies that perceived risk is negatively associated with perceived usefulness, attitude toward technology, and behavioural intention to use technology (e.g., Gefen, Karahanna, and Straub, 2003; Featherman and Pavlou, 2003; Jarvenpaa and Tractisnky, 1999).

As shown at Figure 3, the results of PLS analysis using SmartPLS software (Ringle, Wende, and Will, 2005) present that the perceived risk significantly affects all of the consequential variables. The directions of the relationships (negative effect) are concurrent with findings of extant studies ( $b=-0.45$ to usefulness, $b=-0.12$ to attitude, and $b=-0.44$ to intention, $p<0.001)$. Checking $R^{2}$ values, perceived risk predicts $20 \%$ of variance for usefulness, $54 \%$ of attitude, and $36 \%$ of intention variables. It can be said that these values meet the reasonable criteria over 0.19 to confirm the model validity (Hair et al., 2012). Then, the effect size of the path models was tested to explain the variance of attitude toward and behavioural intention to use smartphones to book a hotel, based upon Cohen $f^{2}$ approach (see Cohen, 1988). The effect size $f^{2}$ for attitude and intention are 0.03 (small effect) and 0.24 
(medium effect), respectively. Last, a set of test to check the model's predictive validity by adopting Stone-Geisser's $Q^{2}$ using a blindfolding procedure was conducted. It suggests that the model is able to provide a prediction of the endogenous latent variable's indicators and shows a synthesis of function fitting and cross validation (Hair et al., 2012). The values of $Q^{2}$ (the relative impact of predictive relevance) are above zero $\left(Q^{2}=0.12\right.$ for usefulness, 0.36 for attitude and 0.14 for behavioral intention), which demonstrate that the construct of perceived risk have predictive relevance for the endogenous construct under consideration.

[Insert Figure 3 here]

\section{Conclusion and Implications}

The increasing prevalence of smartphone use for travel experiences is not yet matched by the rate of mobile phone adoption for travel purchases. The low level of mobile booking in tourism contexts signifies the importance of investigating the perceived risk that inhibits consumers from purchasing travel products through smartphones. By analysing data collected from travellers who are mobile phone users, this study tested and confirmed perceived risk a multidimensional factor consisting of different risk facets. The results demonstrate perceived risk associated with mobile booking for travel products as a second order variable with significant paths to time risk, financial risk, performance risk, privacy/security risk, psychological risk, physical risk and device risk. However, social risk was excluded from the model due to lack of salience. The results corroborate previous studies that conceptualized facet-based perceived risk (e.g., Featherman and Pavlou, 2003), but also validate the merging of privacy risk and security risk (Kim et al. 2008, and Lee 2009) and the inclusion of device risk into the model (e.g., Roehl and Fesenmaier, 1992; Sonmez and Graefe, 1998). With regards to the exclusion of social risk, it can be suggested that due to the high penetration of mobile phones in everyday life, the use of mobile phones to purchase travel products is 
acceptable in the society and would not result in loss of social status. Importantly, the results suggest that security risk and performance risk (i.e., poor product quality) are the most relevant to consumers when evaluating mobile booking. This implies that consumers' concerns about privacy and security as well as the difficulty to judge the quality of travel products on smartphones (i.e., the chance of receiving inferior tourism products/services), contribute greatly to the perception of risk associated with travel booking with mobile devices.

Furthermore, the antecedents of perceived risk were also identified. The results demonstrate negative influences of consumer innovativeness and trust, and positive influence of collection of information on perceived risk, in support of previous research in general purchasing situations (e.g., Aloudat et al., 2014; Cheung and Lee, 2000; Conchar et al., 2004; Dholakia, 2001; Dowling and Staelin, 1994; Junglas and Spitzmüller, 2005; Kim, et al., 2008). Consumer innovativeness traits, which manifest in risk-taking tendency, are confirmed to decrease consumer perception about risk in mobile booking situations. Similarly, the higher the trust on mobile booking systems, which include trust towards vendors and the underlying technology, the less consumers view mobile purchases as risky. It is noteworthy that as an inhibitor of perceived risk, trust has the biggest influence compared to other antecedents, making it an important aspect to consider when designing mobile booking systems. Lastly, the more consumers perceived that smartphones are automatically collecting personal information, the more they perceive risk associated with mobile booking. The results also confirmed the predictive validity of perceived risk in explaining perceived usefulness of smartphones for mobile booking (i.e., a positive evaluation of the systems), attitude toward mobile travel booking, and behavioural intention associated with purchasing travel products using smartphones (in support of, e.g., Gefen, Karahanna, and Straub, 2003; Featherman and Pavlou, 2003; Jarvenpaa et al., 1999). A series of tests including accountability of the 
endogenous variables, Cohen's effect size and Stone-Geisser's $Q^{2}$ consistently verifies the revised facets of perceived risk.

Accordingly, this study provides theoretical implications to tourism literature. This study is the first to define perceived risk of using mobile devices for purchasing travel products. Several tourism researchers who investigated perceived risk mainly focused on the role of risk in decision-making behaviours (see Williams and Baláž, 2015). Among them, a relevant study conducted by Sharifpour, Walters, Ritchie, and Winter (2013) indicated the effect of prior knowledge as an antecedent to explain perceived risk and subsequent information search behaviours broadly composing internal and external sources. Contributing to the extant literature in tourism field, this research, in particular, identified sub-facets of perceived risk specifically applied to tourism and technology. This includes elimination of social risk, combination of security and privacy risk, and inclusion of device risk. It corresponds to arguments in previous research, stating that the facets of risk should be established with a particular consumption situation an individual confronts (Conchar et al., 2004; Dowling and Staelin, 1994). Additionally, this study identified antecedents of perceived risk closely related to mobile users, which include innovativeness, trust, and personal data collection, suggesting the ways to alleviate perceived risk.

This generates important implications for service providers and vendors (e.g., hotels) as well as designers of mobile applications to target the antecedents that help reduce perceived risk. This could be done by promoting the inhibitor factors (innovativeness, trust, visibility) and repressing the promoter of perceived risk (collection). While innovativeness traits are linked to personal characteristics of consumers and imply targeting certain market segments that are prone to adopting new things, service providers and technology designers can increase trust and visibility by making the processes and outcomes associated with mobile booking more easily accessible for travellers. For example, for new applications, an 
easy-to-follow instruction in contexts relevant to consumers (e.g., using first-person-view videos or personas that consumers can associate themselves with) with an explanation on support processes that are not apparent (i.e., back-end) will assist with observability of the applications. Further, as applications are used by early adopters, it is important to showcase the positive outcomes to support outcome demonstrability (e.g., by highlighting positive reviews and/or testimonials at point of sale). Demonstrating the positive outcomes of mobile booking will also increase trust (i.e., that vendors provide products and services at or above the expected level of quality), which, in turn, will reduce perceived risk. Additionally, assuring travellers that sensitive information is only collected to better understand their needs and preferences in order to personalize the services offered and clarifying the parties who have access to this information will also assist in reducing perceived risk.

While this research contributes to a better conceptualization of facet-based perceived risk in mobile travel booking context, it does not provide an alternative explanation regarding the intricacies of the relationships between perceived risk and its antecedents. For example, multiple studies tested different relationships between perceived risk and trust in terms of where the influence originates from (i.e., antecedents vs. consequences). While the conceptual model in this study was developed following a validated framework, future studies verifying different models will provide further support for the theorizing of perceived risk. Additionally, the antecedents included in the model are not expected to be inclusive of all possible factors, especially with regards to consumption contexts. Future research should consider other factors that may contribute to increasing or reducing perceived risk in different consumption situations across different tourism destinations. Lastly, the risk facets and their influences on mobile adoption might be varied for different product categories and decision making phases in tourism. Along with current study that focuses on hotel bookings as a pretrip decision, future research is suggested to consider other travel products (e.g., flights, 
restaurants, shopping, etc.) across different stages of travel decision making process (i.e., pretrip and on-site decisions). 


\section{References}

Agarwal, R., and J. Prasad. (1998). “A Conceptual and Operational Definition of Personal Innovativeness in the Domain of Information Technology." Information systems research, 9 (2): 204-15.

Aldás-Manzano, J., C. Lassala-Navarré, C. Ruiz-Mafé, and S. Sanz-Blas. (2009). "The Role of Consumer Innovativeness and Perceived Risk in Online Banking Usage." International Journal of Bank Marketing, 27 (1): 53-75.

Aloudat, A., K. Michael, X. Chen, and M. M. Al-Debei. (2014). "Social Acceptance of Location-based Mobile Government Services for Emergency Management." Telematics and Informatics, 31 (1): 153-71.

Amaro, S., and P. Duarte. (2015). “An Integrative Model of Consumers' Intentions to Purchase Travel Online.” Tourism Management, 46: 64-79.

Anckar, B., and D. D’Incau. (2002). "Value Creation in Mobile Commerce: Findings from Consumer Survey.” Journal of Information Technology Theory and Application, 4 (1): 43-64.

Bagozzi, R. P., and Y. Yi. (2012). "Specification, Evaluation, and Interpretation of Structural Equation Models.” Journal of the Academy of Marketing Science, 40 (1): 8-34.

Bhatnagar, A., and S. Ghose. (2004). "Segmenting Consumers based on the Benefits and Risks of Internet Shopping.” Journal of Business Research, 57: 1352-360.

Bhatnagar, A., S. Misra, and H. R. Rao. (2000). “On Risk, Convenience, and Internet Shopping Behaviour." Communications of the ACM, 43 (11): 98-105.

Boksberger, P. E., T. Bieger, and C. Laesser. (2007). "Multidimensional Analysis of Perceived Risk in Commercial Air Travel.” Journal of Air Transport Management, 13 (2): $90-6$. 
Bonoma, T. V., and W. J. Johnston. (1979). “Decision Making under Uncertainty: A Direct Measurement Approach.” Journal of Consumer Research, 6 (2): 177-91.

Brislin, R. (1986). The Wording and Translation of Research Instruments. In Lonne, W. and Berry, J. (eds) Field Methods in Cross-Cultural Research. Newbury Park, CA: Sage. Bromiley, P., and S. P. Curley. (1992). Individual Differences in Risk Taking. In Yates, F.F. (Ed.), Risk Taking Behavior (pp. 87-132). Chichester, UK: Wiley.

Chen, L.S-L., Y-H. Lee, and S-T Wang. (2012). "Impact of Intangibility on Perceived Risk Associated with Online Games.” Behaviour and Information Technology, 31 (10): 1021-32.

Cheung, C., and M. K. O. Lee. (2000). "Trust in Internet Shopping: A Proposed Model and Measurement Instrument." In Proceedings of the $6^{\text {th }}$ Americas Conference on Information Systems: pp. 681-689.

Citrin, A.V., D. E. Sprott, S. N. Silverman, and Jr. D. E. Stem. (2000). “Adoption of Internet Shopping: The Role of Consumer Innovativeness." Industrial Management and Data Systems, 100 (7), 294-300.

Conchar, M. P., G. M. Zinkhan, C. Peters, and S. Olavarrieta. (2004). “An Integrated Framework for the Conceptualization of Consumers' Perceived-Risk Processing." Journal of the Academy of Marketing Science, 32 (4): 418-36.

Couture, A., M. Arcand, S. Sénécal, and J.-F. Oullet. (2015). "The Influence of Tourism Innovativeness on Online Consumer Behavior." Journal of Travel Research, 54 (1): 66-79.

Crespo, A. H., I. R. del Bosque, and M. M. G. de los Salmones. (2009). “The Influence of Perceived Risk on Internet Shopping Behavior: A Multidimensional Perspective.” Journal of Risk Research, 12 (2): 259-77. 
Cunningham, S. (1967). The major dimensions of perceived risk. In: D. Cox (Ed.), Risk Taking and Information Handling in Consumer Behavior. Harvard University Press, Cambridge, MA.

Cunningham, L. F., J. H. Gerlach, M. D. Harper, and C. E. Young. (2005). “Perceived Risk and the Consumer Buying Process: Internet Airline Reservations.” International Journal of Service Industry Management, 16 (4): 357-72.

Currim, I. S., and R. K. Sarin. (1983). “A Procedure for Measuring and Estimating Consumer Preferences under Uncertainty.” Journal of Marketing Research, 20 (3): 249-56.

Deutch, M. (1960). "Trust, Trustworthiness and the F Scale." Journal of Abnormal and Social Psychology, 61 (1): 138-40.

Dewey, J. (1910). How we think. Boston: D.C. Heath \& Co.

Dholakia, U. M. (2001). “A Motivational Process Model of Product Involvement and Consumer Risk Perception.” European Journal of Marketing, 35 (11/12): 1340-62.

Donthu, N., and A. Garcia. (1999). “The Internet Shopper.” Journal of Advertising Research, 39 (3): 52-8.

Dowling, G. R., and R. Staelin. (1994). “A Model of Perceived Risk and Intended RiskHandling Activity." Journal of Consumer Research, 21: 119-34.

Eggert, A. (2006). “Intangibility and Perceived Risk in Online Environment.” Journal of Marketing Management, 22 (5/6): 553-72.

eMarketer (2015). “By 2016, Most Digital Travel Bookers Will Use Mobile Devices”, http://www.emarketer.com/Article.aspx?R=1013248\&ecid=MX1086\#sthash.Wi19bkt G.dpuf.

Engel, J. F., D. T. Kollat, and R. D. Blackwell. (1968). “Consumer Behavior.” New York: Holt, Rinehart and Winston, Inc. 
Featherman, M. S., and P. A. Pavlou. (2003). "Predicting E-Services Adoption: A Perceived Risk Facets Perspective.” International Journal of Human-Computer Studies, 59 (4): 451-74.

Forsythe, S. M., and B. Shi. (2003). "Consumer Patronage and Risk Perceptions in Internet Shopping." Journal of Business Research, 56: 867-75.

Fuchs, G., and A. Reichel. (2006). "Tourist Destination Risk Perception: The Case of Israel." Journal of Hospitality and Leisure Marketing, 14 (2): 81-106.

Gefen, D., E. Karahanna, D. W. Straub. (2003). "Trust and TAM in Online Shopping: An Integrated Model.” MIS Quarterly, 27 (1): 51-90.

Gefen, D., V. S. Rao, and N. Tractinsky. (2003). "The Conceptualization of Trust, Risk, and Their Relationship in Electronic Commerce: The Need for Clarifications." In Proceedings of the $36^{\text {th }}$ Hawaii International Conference on Systems Sciences (HICSS) 2003.

Goldsmith, R. E., and C. F. Hofacker. (1991). "Measuring Consumer Innovativeness.” Journal of the Academy of Marketing Science, 19 (3): 209-21.

Hair, J. F., M. Sarstedt, C. M. Ringle, and J. A. Mena. (2012). “An Assessment of the Use of Partial Least Squares Structural Equation Modeling in Marketing Research.” Journal of the Academy of Marketing Science, 40 (3): 414-33.

Hirunyawipada, T., and A. K. Paswan. (2006). "Consumer Innovativeness and Perceived Risk: Implications for High Technology Product Adoption.” Journal of Consumer Marketing, 23 (4): 182-98.

Hu, L., and P. M. Bentler. (1999). "Cutoff Criteria for Fit Indexes in Covariance Structure Analysis: Conventional Criteria versus New Alternatives.” Structural Equation Modeling, 6: 1-55. 
Jacoby, J., and L. B. Kaplan. (1972). "The Components of Perceived Risk.” Advances in consumer research, 3 (3): 382-3.

Jarvenpaa, S. L., and P. A. Todd. (1996). “Consumer Reactions to Electronic Shopping on the World Wide Web.” International Journal of Electronic Commerce, 1 (2): 59-88.

Jarvenpaa, S. L., and N. Tractinsky. (1999). "Consumer Trust in an Internet Store: A CrossCultural Validation.” Journal of Computer-Mediated Communication, 5 (2): 1-33.

Junglas, I., and C. Spitzmüller. (2005). “A Research Model for Studying Privacy Concerns Pertaining to Location-based Services.” In: Proceedings of the 38th Annual Hawaii International Conference on System Sciences (HICSS’05), Hawaii, January 3-6, 2005, viewed 22 August 2007, IEEEXplore Database.

Kahneman, D., and A. Tversky. (1979). "Prospect Theory: An Analysis of Decision under Risk." Econometrica, 47 (2): 263-91.

Karahanna, E., D. W. Straub, and N. L. Chervany. (1999). “Information Technology Adoption across Time: A Cross-Sectional Comparison of Pre-Adoption and Postadoption Beliefs.” MIS Quarterly, 23 (2): 183-213.

Kim, D. J., D. L. Ferrin, and H. R. Rao. (2008). “A Trust-based Consumer Decision-Making Model in Electronic Commerce: The Role of Trust, Perceived Risk, and Their Antecedents.” Decision Support Systems, 44: 544-64.

Kim, L. H., D. J. Kim, and J. K. Leong. (2005). “The Effect of Perceived Risk on Purchase Intention in Purchasing Airline Tickets Online.” Journal of Hospitality and Leisure Marketing, 13 (2): 33-53.

Kim, L. H., H. Qu, and D. J. Kim. (2009). “A Study of Perceived Risk and Risk Reduction of Purchasing Air-Tickets Online.” Journal of Travel and Tourism Marketing, 26: 20324. 
Kim, M-K., Y. Chang, S. F. Wong, and M-C. Park. (2013). “The Effect of Perceived Risks and Switching Barriers on the Intention to Use Smartphones among Non-Adopters in Korea." Information Development, 31 (3): 258-69.

Kline, R. B. (2010). Principles and practice of structural equation modeling. New York: Guilford.

Ko, H., J. Jung, J. Y. Kim, and S. W. Shim. (2004). “Cross-Cultural Differences in Perceived Risk of Online Shopping.” Journal of Interactive Advertising, 4 (2): 20-9.

Kuhlmeier, D., and G. Knight. (2005). “Antecedents to Internet-based Purchasing: A Multinational Study.” International Marketing Review, 22 (4): 460-73.

Law, R., and R. Leung. (2000). “A Study of Airlines' Online Reservation Services on the Internet.” Journal of Travel Research, 39 (2): 202-11.

Lee, M-C. (2009). "Factors Influencing the Adoption of Internet Banking: An Integration of TAM and TPB with Perceived Risk and Perceived Benefit." Electronic Commerce Research and Applications, 8: 130-41.

Lee, M. S. Y., P. J. McGoldrick, K. A. Keeling, and J. Doherty. (2003). “Using ZMET to Explore Barriers to the Adoption of 3G Mobile Banking Services.” International Journal of Retail and Distribution Management, 31 (6): 340 - 8.

Leung, L., and R. Wei. (1999). "Who are the Mobile Phone Have-Nots? Influences and Consequences." New Media and Society, 1 (2): 209-26.

Lim, N. (2003). “Consumers' Perceived Risk: Sources versus Consequences.” Electronic Commerce Research and Applications, 2: 216-28.

Limayem, M., M. Khalifa, and A. Frini. (2000). "What Makes Consumers Buy from Internet? A Longitudinal Study of Online Shopping.” IEEE Transactions on Systems, Man and Cybernetics: Part A (Systems and Humans), 30 (4): 421-32. 
Lin, P. J., E. Jones, and S. Westwood. (2009). "Perceived Risk and Risk-Relievers in Online Travel Purchase Intentions." Journal of Hospitality Marketing and Management, 18 (8): $782-810$.

Luo, X., H. Li, J. Zhang, and J. P. Shim. (2010). "Examining Multi-Dimensional Trust and Multi-Faceted Risk in Initial Acceptance of Emerging Technologies: An Empirical Study of Mobile Banking Services.” Decision Support Systems, 46: 222-34.

Martins, C., T. Oliveira, and A. Popovič. (2014). "Understanding the Internet Banking Adoption: A Unified Theory of Acceptance and Use of Technology and Perceived Risk Application.” International Journal of Information Management, 34 (1): 1-13.

Mayer, R. C., J. H. Davis, and F. D. Schoorman. (1995). "An Integrative Model of Organizational Trust". Academy of Management Review, 20 (3): 709-34.

McCorkle, D. E. (1990). “The Role of Perceived Risk in Mail Order Catalog Shopping.” Journal of Direct Marketing, 4 (4): 26-35.

Mitchell, V. W. (1992). “Understanding Consumers' Behaviour: Can Perceived Risk Theory Help?" Management Decision, 30 (3): 26-31.

Mitchell, V. W. (1999). “Consumer Perceived Risk: Conceptualisations and Models." European Journal of Marketing, 33 (1/2): 163-95.

Mitchell, V. W., F. Davies, L. Moutinho, and V. Vassos. (1999). “Using Neural Networks to Understand Service Risk in the Holiday Product." Journal of Business Research, 46 (2): $167-81$.

Moore, G. C., and I. Benbasat. (1991). "Development of an Instrument to Measure the Perceptions of Adopting an Information Technology Innovation.” Information Systems Research, 2 (3): 192-222.

Moreira, P. (2007). "Stealth Risks and Catastrophic Risks: On Risk Perception and Crisis Recovery Strategies.” Journal of Travel and Tourism Marketing, 23 (2): 15-27. 
Nepomuceno, M. V., M. Laroche, and M-O. Richard. (2013). "How to Reduce Perceived Risk When Buying Online: The Interactions between Intangibility, Product Knowledge, Brand Familiarity, Privacy and Security Concerns.” Journal of Retailing and Consumer Services, 21: 619-29.

Nunkoo, R., and H. Ramkissoon. (2013). “Travelers' E-Purchase Intent of Tourism Products and Services.” Journal of Hospitality Marketing and Management, 22 (5): 505-29.

Nunnally, J. C., and I. H. Bernstein. (1994). Psychometric Theory (3 ${ }^{\text {rd }}$ ed.). New York: McGraw-Hill.

Park, S., and J. L. Nicolau. (2015). “Asymmetric Effects of Online Consumer Reviews." Annals of Tourism Research, 50: 67-83.

Park, S., and Y. Reisinger. (2012). "Cultural Differences in Tourism Web Communication: A Preliminary Study.” Tourism Analysis, 17: 761-74.

Podsakoff, P. M., S. B. MacKenzie, J. Y. Lee, and N. P. Podsakoff. (2003). “Common Method Biases in Behavioral Research: A Critical Review of the Literature and Recommended Remedies.” Journal of Applied Psychology, 88: 879-903.

Ringle, C., M. S. Wende, and S. Will. (2005). SmartPLS 2.0 (M3) Beta, Hamburg. http://www.smartpls.de

Roehl, W., and D. R. Fesenmaier. (1992). "Risk Perceptions and Pleasure Travel: An Exploratory Analysis." Journal of Travel Research, 30 (4): 17-26.

Rogers, E. M. (1995). Diffusions of Innovation. New York: The Free Press.

Rotchanakitumnuai, S. (2007). The Important Risk Factors of E-Government Service Adoption, Wireless Communications, Networking and Mobile Computing, WiCom 2007. International Conference on IEEE, pp. 3657-3660.

Ruiz-Mafé, C., S. Sanz-Blas, and J. Aldás-Manzano. (2009). "Drivers and Barriers to Online Airline Ticket Purchasing." Journal of Air Transport Management, 15: 294-8. 
San-Martín, H. and A. Herrero. (2012). "Influence of the User's Psychological Factors on the Online Purchase Intention in Rural Tourism: Integrating Innovativeness to the UTAUT Framework." Tourism Management, 33 (1): 341-50.

Seabra, C., S. Dolnicar, J. L. Abrantes, and E. Kastenholz. (2013). "Heterogeneity in Risk and Safety Perceptions of International Tourists." Tourism Management, 36: 502-10.

Shikhar, S. T., T. Sego, and N. Chanvarasuth. (2003). "Strategic Use of Bundling for Reducing Consumers' Perceived risk Associated with the Purchase of New-Tech Products." Journal of Marketing Theory and Practice, 11 (3): 71-84.

Sitkin, S. B., and A. L. Pablo. (1992). "Reconceptualizing the Determinants of Risk Behavior." Academy of Management Review, 17 (1): 9-38.

Sonmez, S. F., and A. R. Graefe. (1998). "Determining Future Travel Behavior from Past Travel Experience and Perceptions of Risk and Safety." Journal of Travel Research, 37: 171-7.

Sharifpour, M., G. Walters, B. W. Ritchie, and C. Winter. (2013). "Investigating the Role of Prior Knowledge in Tourist Decision Making: A Structural Equation Model of Risk Perceptions and Information search." Journal of Travel Research: 0047287513500390.

Tsaur, S-H., G-H. Tzeng, and K-C. Wang. (1997). "Evaluating Tourist Risks from Fuzzy Perspectives." Annals of Tourism Research, 24 (4): 795-812.

Tussyadiah, I. P. (2015). “The Influence of Innovativeness on On-Site Smartphone Use among American Travelers: Implications for Context-based Push Marketing.” Journal of Travel and Tourism Marketing, OnlineFirst. doi: 10.1080/10548408.2015.1068263 von Hippel, E. (1986). "Lead Users: A Source of Novel Product Concepts." Management Science, 32 (7): 791-805.

Wang, D., S. Park, and D. R. Fesenmaier. (2012). "The Role of Smartphones in Mediating the Touristic Experience.” Journal of Travel Research, 51 (4): 371-87. 
Williams, A. M., and V. Baláž. (2013). "Tourism Risk and Uncertainty Theoretical Reflections." Journal of Travel Research 54 (3): 271-87.

Wu, J. H., and S. C. Wang. (2005). "What Drives Mobile Commerce? An Empirical Evaluation of the Revise Technology Acceptance Model.” Information and Management, 42: 719-29.

Yang, Y., and J. Zhang. (2009). "Discussion on the Dimensions of Consumers' Perceived Risk in Mobile Service.” The Proceeding of 2009 Eighth International Conference on Mobile Business. Washington, DC: IEEE Computer Society, 261-266.

Zaltman, G., R. Duncan, and J. Holbek. (1973). Innovations and Organizations. New York: Wiley.

Zimmer, J. C., R. E. Arsal, M. Al-Marzouq, and Y. Grover. (2010). “Investigating Online Information Disclosure: Effects of Information Relevance, Trust and Risk." Information and Management, 47: 115-23. 


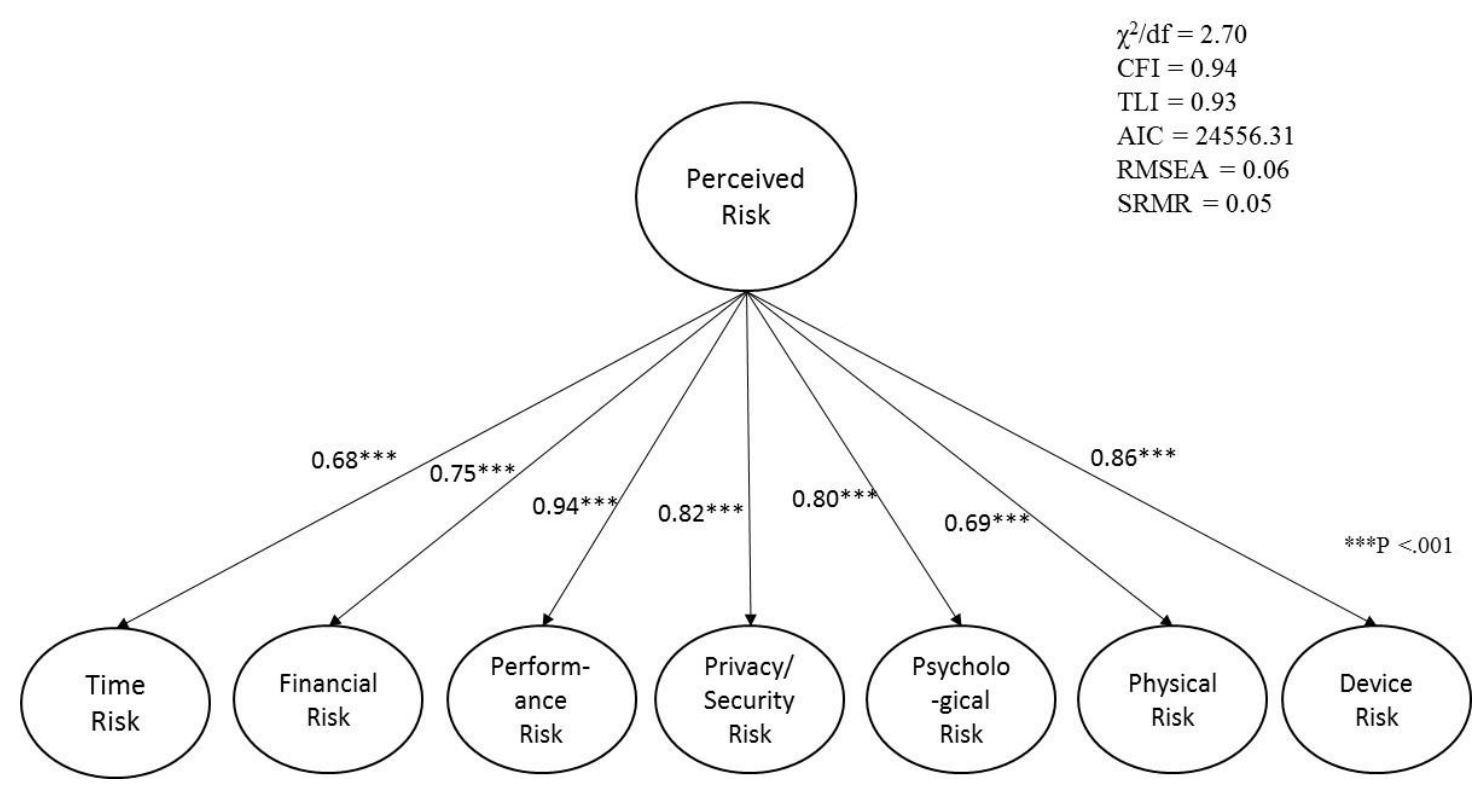

Figure 1. Revised Second-Order CFA of Perceived Risk Facets Model 


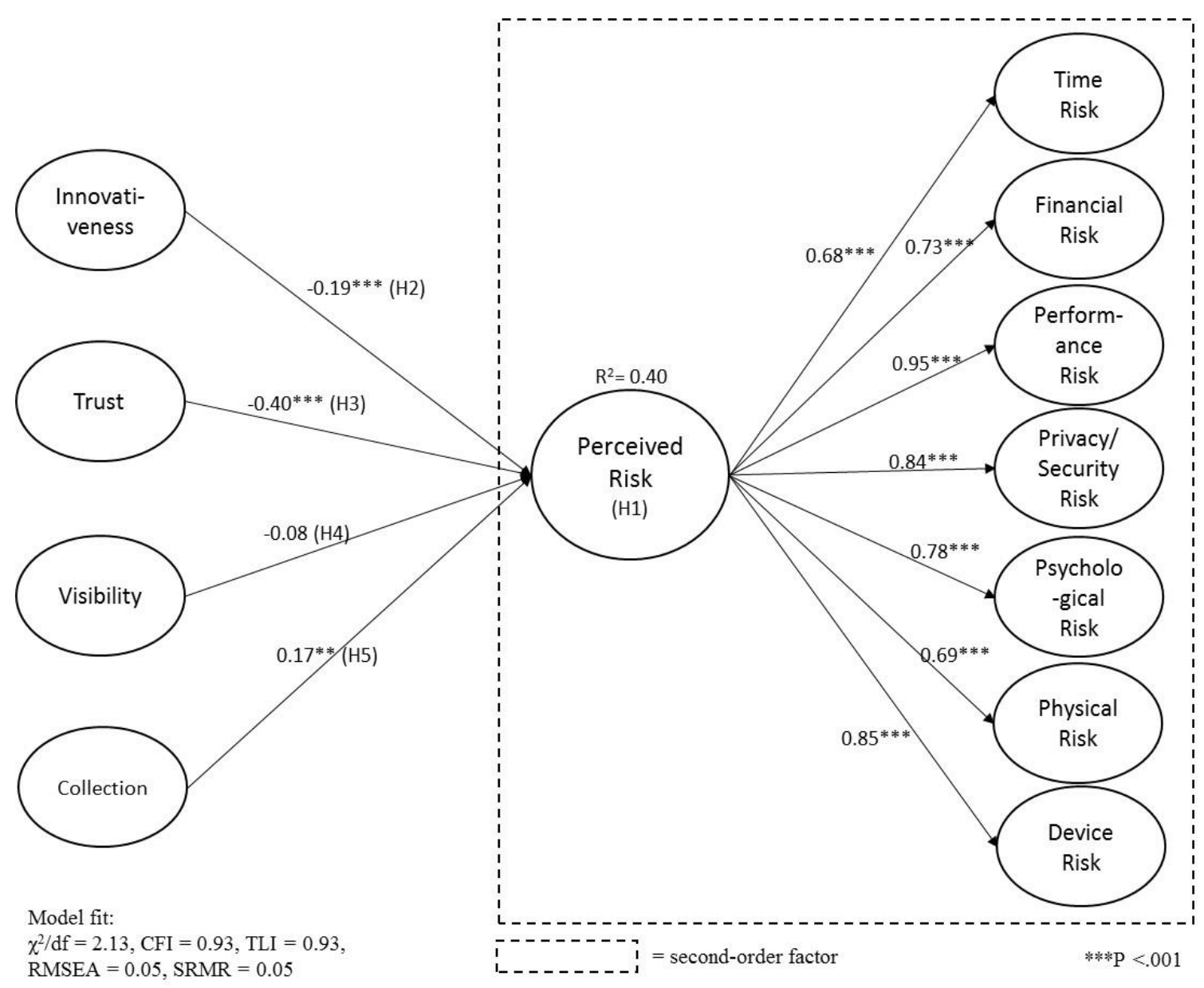

Figure 2. Structural Model 


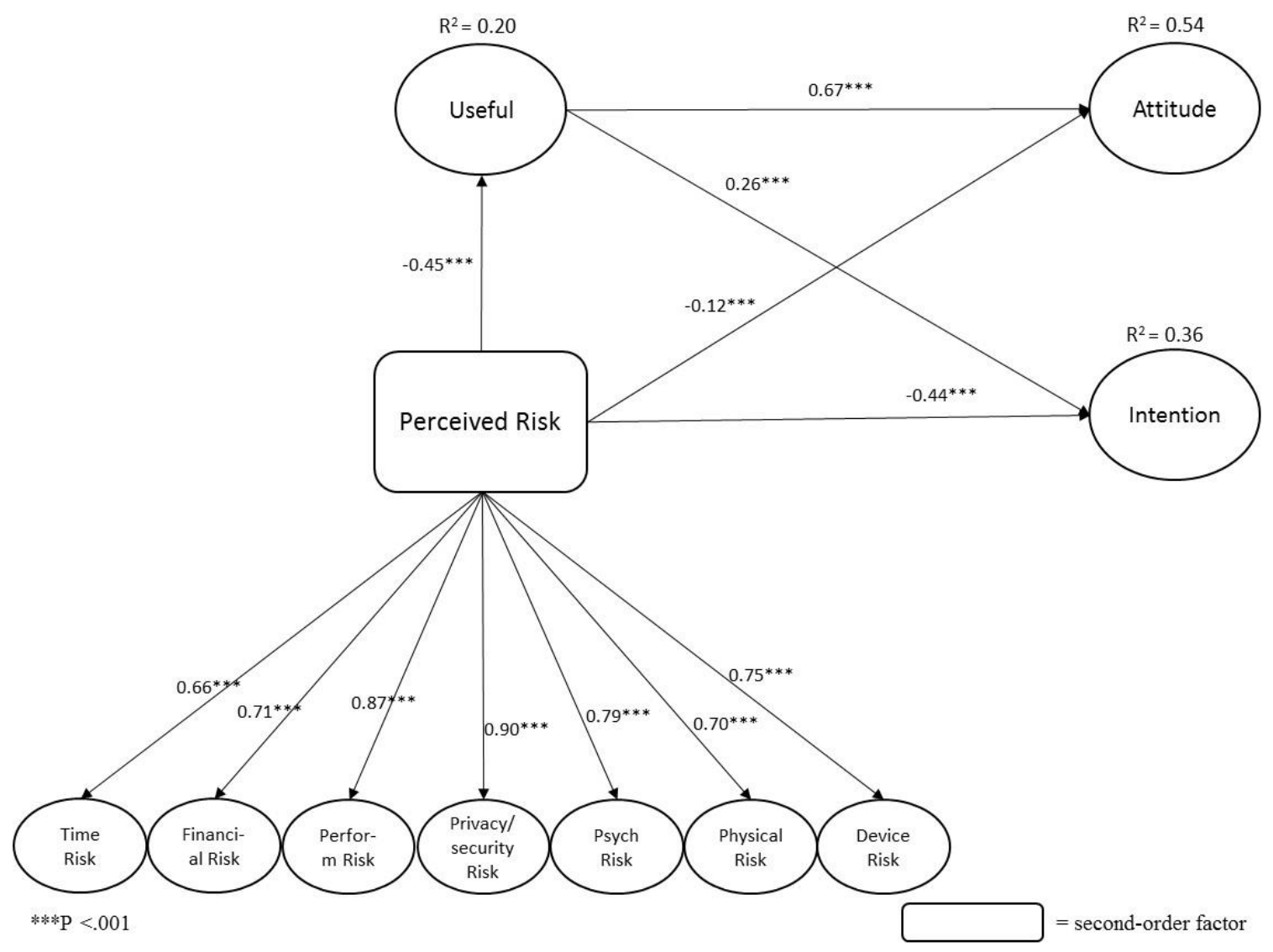

Figure 3. Predictive Validity of Perceived Risk 
Table 1. Summary of Previous Literature about Perceived Risk

\begin{tabular}{|c|c|c|c|c|c|c|c|c|c|c|}
\hline & Financial & Performance & Social & Physical & Psychological & Time & Personal & Privacy & Security & $\begin{array}{c}\text { Technology } \\
\text { (device related) }\end{array}$ \\
\hline \begin{tabular}{l}
\multicolumn{1}{c}{ E-service in general } \\
Jarvenpaa and Todd (1996) \\
Featherman and Pavlou (2003) \\
Lim (2003) \\
Lee (2009) \\
Chen et al. (2012) \\
Martins et al. (2014) \\
Nepomuceno et al., (2014)
\end{tabular} & $\begin{array}{l}\sqrt{ } \\
\sqrt{ } \\
\sqrt{ } \\
\sqrt{ } \\
\sqrt{ } \\
\sqrt{ } \\
\sqrt{ }\end{array}$ & $\begin{array}{l}\sqrt{ } \\
\sqrt{ } \\
\sqrt{ } \\
\sqrt{ } \\
\sqrt{ } \\
\sqrt{ } \\
\sqrt{ }\end{array}$ & $\begin{array}{l}\sqrt{ } \\
\sqrt{ } \\
\sqrt{ } \\
\sqrt{ } \\
\sqrt{ } \\
\sqrt{ }\end{array}$ & $\begin{array}{l}\sqrt{ } \\
\sqrt{ }\end{array}$ & $\begin{array}{l}\sqrt{ } \\
\sqrt{ } \\
\sqrt{ } \\
\sqrt{ }\end{array}$ & $\begin{array}{l}\sqrt{ } \\
\sqrt{ } \\
\sqrt{ } \\
\sqrt{ } \\
\sqrt{ } \\
\sqrt{ }\end{array}$ & $\sqrt{ }$ & $\begin{array}{l}\sqrt{ } \\
\sqrt{ } \\
\sqrt{ } \\
\sqrt{ } \\
\sqrt{ }\end{array}$ & $\sqrt{ }$ & $\sqrt{ }$ \\
\hline $\begin{array}{l}\quad \text { M-service in general } \\
\text { Yang and Zhang (2009) } \\
\text { Luo et al. (2010) } \\
\text { Kim et al., (2013) }\end{array}$ & $\begin{array}{l}\sqrt{ } \\
\sqrt{ } \\
\sqrt{ }\end{array}$ & $\begin{array}{l}\sqrt{ } \\
\sqrt{ }\end{array}$ & $\sqrt{ }$ & $\sqrt{ }$ & $\sqrt{ }$ & $\sqrt{ }$ & & $\begin{array}{l}\sqrt{ } \\
\sqrt{ }\end{array}$ & & $\begin{array}{l}\sqrt{ } \\
\sqrt{ }\end{array}$ \\
\hline $\begin{array}{l}\quad \text { E-service in Tourism } \\
\text { Kim, et al., (2005; 2009) } \\
\text { Cunningham et al., (2005) } \\
\text { Ruiz-Mafe' et al. (2009) } \\
\text { Nunkoo \& Ramkissoon (2013) }\end{array}$ & $\begin{array}{l}\sqrt{ } \\
\sqrt{ }\end{array}$ & $\begin{array}{l}\sqrt{ } \\
\sqrt{ } \\
\sqrt{ }\end{array}$ & $\begin{array}{l}\sqrt{ } \\
\sqrt{ }\end{array}$ & $\begin{array}{l}\sqrt{ } \\
\sqrt{ }\end{array}$ & $\begin{array}{l}\sqrt{ } \\
\sqrt{ } \\
\sqrt{ }\end{array}$ & $\begin{array}{l}\sqrt{ } \\
\sqrt{ } \\
\sqrt{ }\end{array}$ & & $\sqrt{ }$ & $\sqrt{ }$ & \\
\hline
\end{tabular}


Table 2. The Results of Confirmatory Factor Analysis

\begin{tabular}{|c|c|c|c|c|c|}
\hline Construct & Items & Factor loadings & t-value & $\begin{array}{l}\text { Cronbach } \\
\text { alpha }\end{array}$ & Mean (SD) \\
\hline \multirow[t]{3}{*}{ Social risk (SR) } & SR1 & 0.63 & 17.74 & 0.80 & $3.53(0.92)$ \\
\hline & SR2 & 0.85 & 30.48 & & \\
\hline & SR3 & 0.81 & 28.12 & & \\
\hline \multirow{2}{*}{ Time risk (TR) } & TR2 & 0.87 & 36.14 & 0.84 & $2.61(1.04)$ \\
\hline & TR3 & 0.84 & 33.43 & & \\
\hline \multirow[t]{3}{*}{ Financial risk (FR) } & FR1 & 0.76 & 30.47 & 0.87 & $2.36(0.91)$ \\
\hline & FR2 & 0.88 & 52.26 & & \\
\hline & FR3 & 0.85 & 44.35 & & \\
\hline \multirow[t]{4}{*}{ Performance risk (PR) } & PR1 & 0.75 & 30.18 & 0.85 & $2.76(0.89)$ \\
\hline & PR2 & 0.76 & 31.32 & & \\
\hline & PR3 & 0.76 & 31.23 & & \\
\hline & PR4 & 0.81 & 39.73 & & \\
\hline \multirow[t]{8}{*}{ Privacy/Security risk (PSR) } & PSR1 & 0.87 & 63.72 & 0.96 & $3.18(0.99)$ \\
\hline & PSR2 & 0.85 & 56.17 & & \\
\hline & PSR3 & 0.89 & 75.33 & & \\
\hline & PSR4 & 0.86 & 63.00 & & \\
\hline & PSR5 & 0.85 & 58.53 & & \\
\hline & PSR6 & 0.85 & 56.91 & & \\
\hline & PSR7 & 0.84 & 52.41 & & \\
\hline & PSR8 & 0.85 & 55.82 & & \\
\hline \multirow[t]{3}{*}{ Psychological risk (PSR) } & PSR1 & 0.84 & 46.16 & 0.90 & $2.31(0.93)$ \\
\hline & PSR2 & 0.91 & 70.16 & & \\
\hline & PSR3 & 0.87 & 56.26 & & \\
\hline \multirow[t]{3}{*}{ Physical risk (PHR) } & PHR 1 & 0.76 & 30.07 & 0.85 & $2.69(0.96)$ \\
\hline & PHR2 & 0.86 & 43.31 & & \\
\hline & PHR3 & 0.81 & 36.88 & & \\
\hline \multirow[t]{3}{*}{ Device risk (DR) } & DR1 & 0.60 & 16.05 & 0.73 & $2.86(0.91)$ \\
\hline & DR2 & 0.79 & 26.98 & & \\
\hline & DR3 & 0.66 & 18.54 & & \\
\hline
\end{tabular}


Table 3. Latent Correlation Analysis

\begin{tabular}{|c|c|c|c|c|c|c|c|c|c|c|c|c|c|}
\hline & CR & 1 & 2 & 3 & 4 & 5 & 6 & 7 & 8 & 9 & 10 & 11 & 12 \\
\hline 1. Social risk & 0.88 & 0.85 & & & & & & & & & & & \\
\hline 2. Time risk & 0.91 & -0.02 & 0.91 & & & & & & & & & & \\
\hline 3. Financial risk & 0.92 & -0.15 & 0.56 & 0.91 & & & & & & & & & \\
\hline 4. Performance risk & 0.91 & 0.04 & 0.73 & 0.75 & 0.85 & & & & & & & & \\
\hline 5. Privacy/security risk & 0.97 & 0.13 & 0.54 & 0.52 & 0.78 & 0.87 & & & & & & & \\
\hline 6. Psychological risk & 0.95 & -0.01 & 0.56 & 0.64 & 0.74 & 0.66 & 0.93 & & & & & & \\
\hline 7. Physical risk & 0.91 & -0.08 & 0.45 & 0.51 & 0.57 & 0.61 & 0.58 & 0.89 & & & & & \\
\hline 8. Device risk & 0.82 & -0.03 & 0.56 & 0.61 & 0.77 & 0.74 & 0.66 & 0.71 & 0.78 & & & & \\
\hline 9. Innovativeness & 0.93 & -0.40 & -0.26 & -0.19 & -0.38 & -0.36 & -0.25 & -0.29 & -0.31 & 0.91 & & & \\
\hline 10. Trust & 0.88 & -0.26 & -0.44 & -0.35 & -0.60 & -0.60 & -0.37 & -0.33 & -0.42 & 0.38 & 0.85 & & \\
\hline 11. Visibility & 0.90 & -0.23 & -0.38 & -0.27 & -0.40 & -0.31 & -0.27 & -0.22 & -0.21 & 0.22 & 0.57 & 0.86 & \\
\hline 12. Collection & 0.94 & 0.08 & 0.23 & 0.21 & 0.35 & 0.44 & 0.22 & 0.25 & 0.29 & -0.13 & -0.42 & -0.17 & 0.87 \\
\hline
\end{tabular}

Note: CR refers to composite reliability; Items on the diagonal (in bold) represent AVE scores 
Table 4. Second-Order CFA of Perceived Risk Facets Model

\begin{tabular}{lcc}
\hline \multicolumn{1}{c}{ Risk facets } & Std path weights & Squared multiple correlation \\
\hline Social risk & $0.326^{* * *}$ & 0.106 \\
Time risk & $0.717^{* * *}$ & 0.514 \\
Financial risk & $0.742^{* * *}$ & 0.551 \\
Performance risk & $0.950^{* * *}$ & 0.903 \\
Privacy/security risk & $0.824 * * *$ & 0.679 \\
Psychological risk & $0.797^{* * *}$ & 0.635 \\
Physical risk & $0.680^{* * *}$ & 0.462 \\
Device risk & $0.818^{* * *}$ & 0.669 \\
\hline$\chi^{2} / \mathrm{df}=2.83, \mathrm{CFI}=0.92, \mathrm{TLI}=0.92, \mathrm{AIC}=27921.52, \mathrm{RMSEA}=0.07, \mathrm{SRMR}=0.10 ;{ }^{* * *} p<0.001$
\end{tabular}


Table 5. Comparison of Model Fit Indices to Second-Order Composite of Perceived Risk

\begin{tabular}{ccccccc}
\hline & $\chi^{2} / \mathrm{df}$ & CFI & TLI & RMSEA & SRMR & AIC \\
\hline Initial model $^{1}$ & 3.08 & 0.91 & 0.90 & 0.07 & 0.11 & 28011.04 \\
Alternative model $^{2}$ with social risk & 2.83 & 0.92 & 0.92 & 0.07 & 0.10 & 27921.52 \\
$\begin{array}{c}\text { Alternative model without } \\
\text { social risk }\end{array}$ & 2.70 & 0.94 & 0.93 & 0.06 & 0.05 & 24556.31 \\
\hline
\end{tabular}

Note: 1 refers the model including separate privacy risk and security risk. 2 refers the model including combined privacy security risk. 
Table 6. Comparison of Model Fit Indices to Test the Common Method Bias

\begin{tabular}{cccccc}
\hline & $\chi^{2} / \mathrm{df}$ & CFI & TLI & RMR & RMSEA \\
\hline Revised model & 2.13 & 0.93 & 0.93 & 0.05 & 0.05 \\
Model with the common method factor & 2.00 & 0.94 & 0.93 & 0.05 & 0.06 \\
\hline
\end{tabular}

